\title{
A New Centromerus from Bulgarian Caves (Araneae, Linyphiidae)
}

\author{
by \\ Christo DELTSHEV*
}

Two years ago I received a collection including $2 \%$ representatives of a very interesting species of Centromerus, collected in "Karangil" cave in East Rhodopes. Later a new collection of $20^{\circ}$ and 3 of representatives of the same species of Centromerus in the same cave was made. This gave me an opportunity to describe a new species, which I call Centromerus milleri in honour of the well known Czechoslovakian arachnologist Prof. Fr. Miller from Brno.

I am especially obliged to Prof. Miller, who revised this material.

\section{Centromerus milleri $\mathrm{n} . \mathrm{sp}$.}

Description of male

Total length $-2.88 \mathrm{~mm}$. Cephalothorax, lenght $-1.35 \mathrm{~mm}$, wide $-1.06 \mathrm{~mm}$, yellow -- brown.

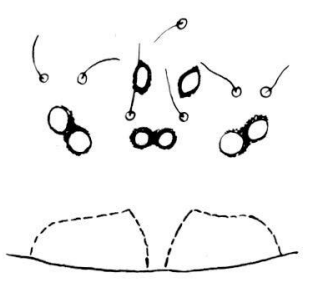

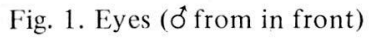

Eyes (fig. 1), well developed, but not very big, surrounded by a narrow black strip. Posterior row $0.37 \mathrm{~mm}$ long, median eyes ca 1.5 diam. apart and 2 diam. from laterals. Anterioir row $0.28 \mathrm{~mm}$ long, medians very small and almost approached, ca 2 diam. from laterals. Clypeus concave, height $-0.23 \mathrm{~mm}$.

Chelicerae, (figs. 2, 3) length $-0.57 \mathrm{~mm}$, wide at the base $-0.28 \mathrm{~mm}$, armed with 3 well developed teeth on outer row and 6 denticles on inner row. The chelicerae have a longitudinal row of minute bristles, close to and parallel with the external border (fig. 3).

Sternum, length $-0.72 \mathrm{~mm}$, wide $-0.72 \mathrm{~mm}$.

Abdomen, length $-1.44 \mathrm{~mm}$, grey.

* Zoological Institute and Museum, Boul. Russki 1, SOFIA, Bulgaria. 
The measurements (in $\mathrm{mm}$ ) of legs:

\begin{tabular}{lllllll}
\hline Leg & Fe & Pt & Ti & Mt & Ta & Total \\
\hline I & 1.67 & 0.37 & 1.67 & 1.50 & 0.95 & 6.16 \\
II & 1.50 & 0.37 & 1.50 & 1.44 & 0.86 & 5.67 \\
III & 1.29 & 0.34 & 1.29 & 1.29 & 0.72 & 4.79 \\
IV & 1.67 & 0.37 & 1.67 & & & \\
\hline
\end{tabular}

Legs yellowish. Femora I with 1 retrolateral spine on apical half and 1 dorsal spine in the middle. All tibiae with 2 dorsal spines.

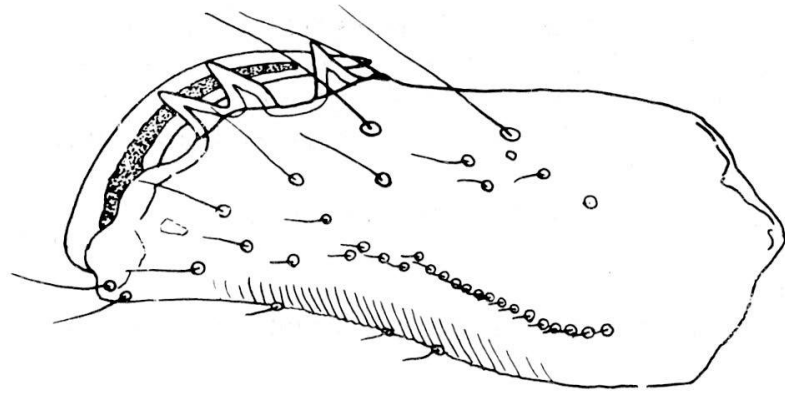

$0.3 \mathrm{~mm}$

Fig. 2. Left ơ chelicera, external view.

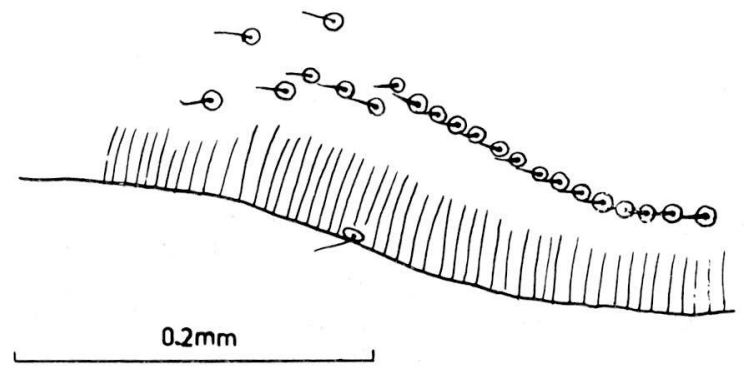

Fig. 3. Longitudinal row of minute bristles on male palp.

Palpus (figs. 4, 5). Tibia and patella without stout spines. Cymbium with long and very characteristic growth. Paracymbium large and prominent, without serrated inner margin. A slender apophysa projects from near the base of palpal organs. Description of female

Total length $-3.46 \mathrm{~mm}$. Cephalothorax, length $-1.50 \mathrm{~mm}$, wide $-1.15 \mathrm{~mm}$, yellow-brown. 
Eyes, well developed but not very big, surrounded by a narrow black strip. Posterior row $0.43 \mathrm{~mm}$ long, median eyes ca one diam. apart and ca 2 diam. from laterals. Anterior row $0.28 \mathrm{~mm}$ long, medians very small and almost approached, ca 2 diam. from laterals. Clypeus concave, height $-0.23 \mathrm{~mm}$.

Chelicerae (fig. 6), length $-0.64 \mathrm{~mm}$, wide at the base $-0.31 \mathrm{~mm}$, armed with 3 well developed teeth. Posterior row with 7 denticles.

Sternum - length $-0.86 \mathrm{~mm}$, wide $-0.72 \mathrm{~mm}$.

Abdomen - length $-2.01 \mathrm{~mm}$, grey.

Legs, yellowish. Femora I with 1 retrolateral spine on apical half and 1 dorsal spine in the middle. All tibiae with 2 dorsal spines.

The measurements (in $\mathrm{mm}$ ) of legs:

\begin{tabular}{lllllll}
\hline Leg & Fe & Pt & Ti & Mt & Ta & Total \\
\hline I & 1.73 & 0.47 & 1.73 & 1.58 & 1.01 & 6.55 \\
II & 1.67 & 0.43 & 1.58 & 1.53 & 0.86 & 6.07 \\
III & 1.44 & 0.40 & 1.29 & 1.21 & 0.69 & 5.03 \\
IV & 1.81 & 0.47 & 1.87 & 1.58 & 1.01 & 6.70 \\
\hline
\end{tabular}

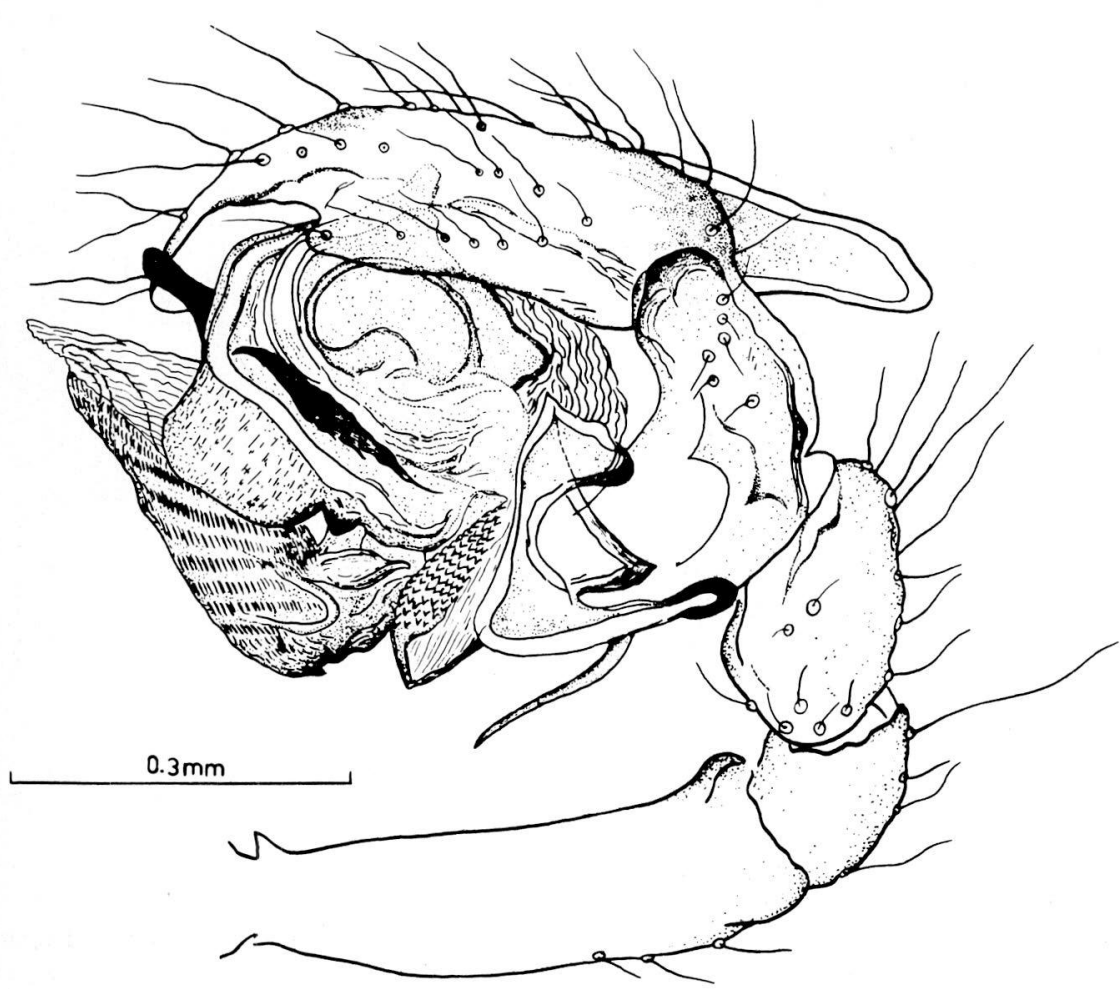

Fig. 4. Left ơ palp, external view. 


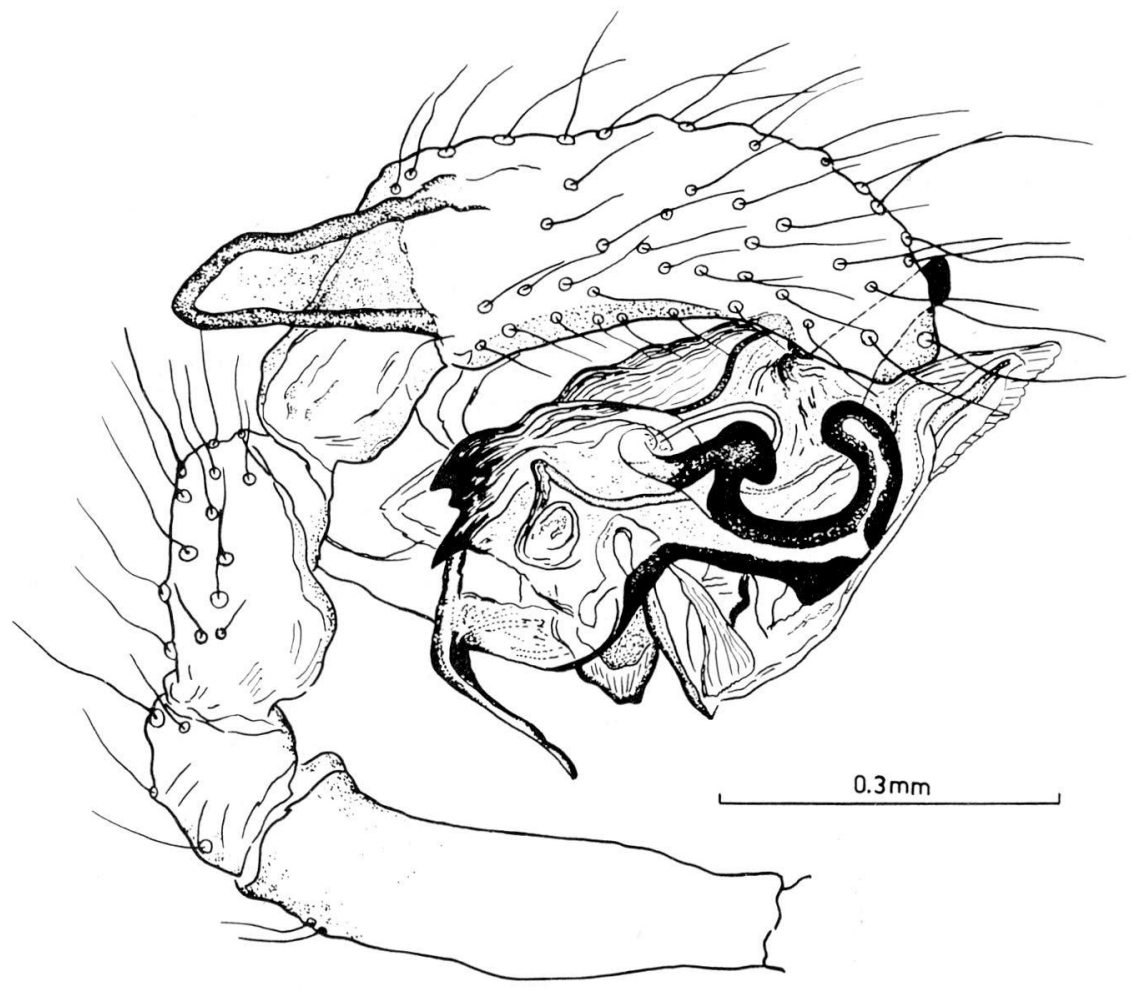

Fig. 5. Left ơ palp, internal view.

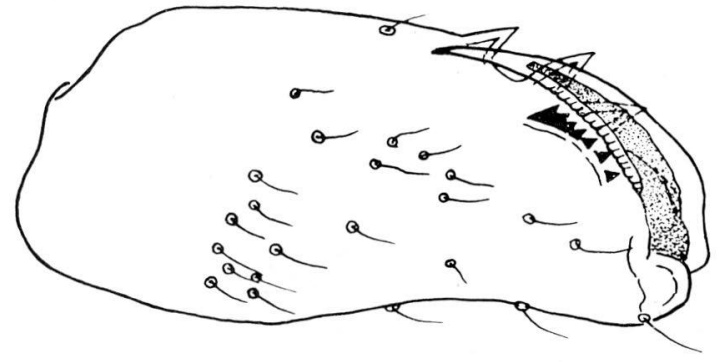

$0.3 \mathrm{~mm}$

Fig. 6. Left $q$ chelicera internal view.

Palpus: $\mathrm{Fe}-0.51 \mathrm{~mm}, \mathrm{Pt}-0.14 \mathrm{~mm}, \mathrm{~Tb}-0.28 \mathrm{~mm}, \mathrm{Tr}-0.57 \mathrm{~mm}$.

Epigyne and vulva presented on figs. 7, 8 and 9 . The epigyne is similar to those of C. pabulator. (Cambr.). 
Fig. 7. Epigyne.
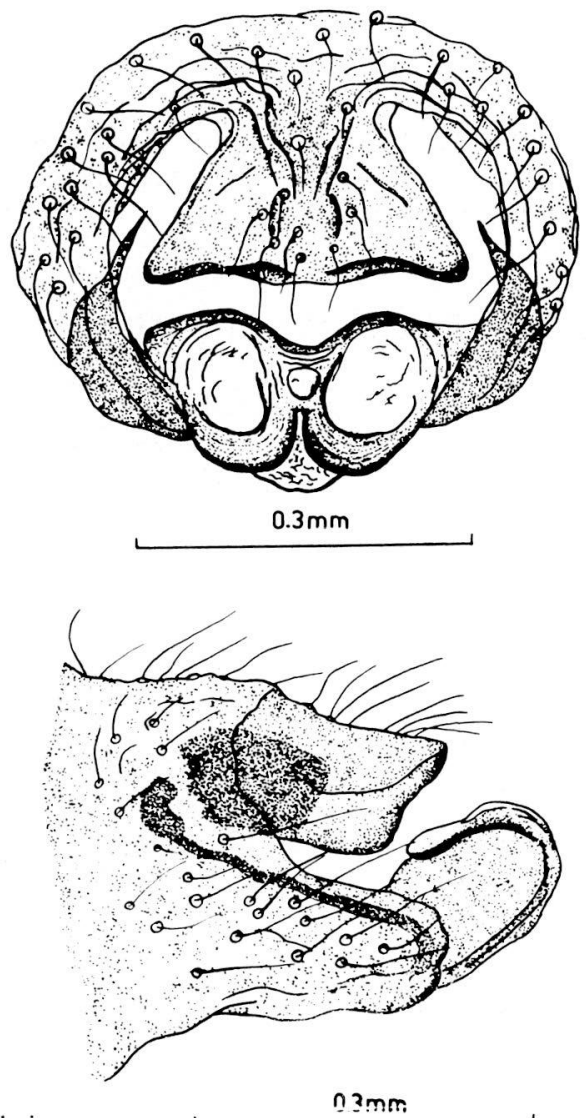

Fig. 8. Epigyne, lateral view.

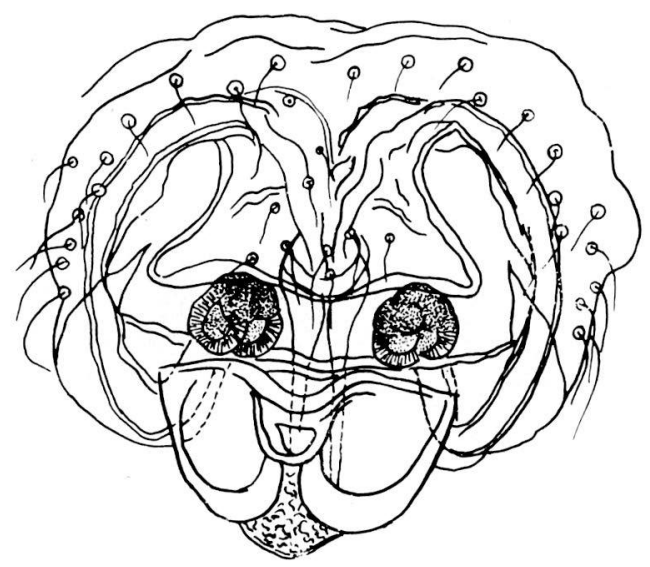

Fig. 9. Vulva. 


\section{DISCUSSION}

Centromerus milleri n. sp. belongs to the group of Centromerus pabulator. The epigyne is similar to those of $C$. pabulator but the base of scapus is not as thin as $C$. pabulator. The male palpus is more differentiated.

\section{MATERIAL AND LOCALITY}

"Karangil" cave near the town of Kartjali (East Rhodopes), 1 t holotype, 3 $q$, 1 \% paratypes, 2.IV.1972 (leg. B. Kolev); 2 \% paratypes, 14.III.1971 (leg. B. Kolev). The type-material is preserved in collections of the Zoological Institute - BAN, Sofia.

\section{SUMMARY}

A new species, Centromerus milleri, is described, which was collected in the cave "Karangil" near the town of Kardjali, Bulgaria. Centromerus milleri n. sp. belongs to the group of $C$. pabulator.

\section{RESUME}

Dans le présent travail est décrite une nouvelle espèce, recueillie dans la grotte "Karangil" près de la ville Kardjali, Bulgarie. Centromerus milleri n. sp. appartient au groupe $C$. pabulator. 